\title{
OPEN Robust, universal, and persistent bud secretion adhesion in horse-chestnut trees
}

\author{
Dagmar Voigt $\mathbb{1}^{1,4} \llbracket$, Jaekang Kim $\mathbb{1}^{2,4}$, Anne Jantschke $\mathbb{1}^{3,4}$ \& Michael Varenberg ${ }^{2,4}$
}

Buds of horse-chestnut trees are covered with a viscous fluid, which remains sticky after long-term exposure to heat, frost, radiation, precipitation, deposition of aerosols and particles, attacks by microbes and arthropods. The present study demonstrates that the secretion does not dry out under arid conditions, not melt at $50^{\circ} \mathrm{C}$, and not change significantly under UV radiation or frost at a microscopic level. It is slightly swellable under wet conditions; and, it universally wets and adheres to substrates having different polarities. Measured pull-off forces do not differ between hydrophilic and lipophilic surfaces, ranging between 58 and $186 \mathrm{mN}$, and resulting in an adhesive strength up to $204 \mathrm{kPa}$. The mechanical and chemical properties of secretion resemble those of pressure-sensitive adhesives. The Raman, infrared, and nuclear magnetic resonance spectra show the clear presence of saturated aliphatic hydrocarbons, esters, free carboxylic acids, as well as minor amounts of amides and aromatic compounds. We suggest a multi-component material (aliphatic hydrocarbon resin), including alkanes, fatty acids, amides, and tackifying terpenoids embedded in a fluid matrix (fatty acids) comprising nonpolar and polar portions serving the universal and robust adhesive properties. These characteristics matter for ecological-evolutionary aspects and can inspire innovative designs of multifunctional, biomimetic pressure-sensitive adhesives and varnishes.

The glistening buds of horse-chestnut trees are covered with a viscous fluid, which is present from the early bud development until its unfolding after about 10-11 months, surviving summer, autumn, and winter conditions ${ }^{1,2}$. This fluid is secreted by the so-called colleters (spherical multicellular glandular trichomes). It spreads over the inner and outer surfaces of six to eight decussate pairs of bud scales, filling the bud scale interspaces and creating a multilayered impregnated structure ${ }^{1,3,4}$. This material protects the developing meristems of the shoot apex and floral buds against environmental stresses, such as high evapotranspiration and dehydration, e.g., ${ }^{5-10}$. Highly reflective plant surfaces may exhibit a marked reduction in water loss through lowering the temperature of a leaf by $10-15^{\circ} \mathrm{C}$ and thus, decreasing the transpiration rate ${ }^{11-13}$. Plant surface mucilages may play a role in water retention due to their ability to absorb water ${ }^{14-16}$. Moreover, superficial plant exudates can repel herbivores and pathogens ${ }^{13,17-20}$, or protect against irradiation ${ }^{21}$.

The viscous fluid released by the horse-chestnut bud colleters is assumably a mixture of resin or oil and gum particles soluble in acetone, e.g., ${ }^{1-3,22}$. Acetone or hexane extractions of entire buds and subsequent chromatography analyses (GC-MS) reveal a heterogeneous, chemically diverse material composed of a nonpolar portion (crystallizing flavonols, small amounts of triterpenes) and a polar syrup-like portion, which is the main mass of the extract. Larger fractions of methylated flavonoid aglycones, such as kaempferoltri- and dimethylether, quercetindi- and trimetylether, myricetin trimethylether, rhamnazin, rhamnocitrin, kaempferide, and isorhamnetin have also been detected ${ }^{23-28}$. Besides antimicrobial properties, flavonoids can absorb the most energetic solar wavelengths (i.e., UV-B, UV-A), decreasing oxidative stress ${ }^{29}$.

This secretion also exhibits a remarkable stickiness; once touched, it is difficult to remove from skin, clothes, and other materials. However, despite biological adhesion attract much research interest lately, plant adhesives received little attention so far, and adhesive properties of horse-chestnut tree secretions remain largely unknown. To this end, knowing about the exposure of horse-chestnut buds to a variety of impacts over time (Fig. 1), we studied the microscopic structure, chemical composition, and, in particular, the adhesive properties of the bud secretion in the context of environmental changes.

${ }^{1}$ Institute for Botany, Faculty of Biology, Technische Universität Dresden, 01062 Dresden, Germany. ${ }^{2}$ George W. Woodruff School of Mechanical Engineering, Georgia Institute of Technology, Atlanta, GA 30332, USA. ${ }^{3}$ Bioanalytical Chemistry, Technische Universität Dresden, 01062 Dresden, Germany. ${ }^{4}$ These authors contributed equally: Dagmar Voigt, Jaekang Kim, Anne Jantschke and Michael Varenberg. ${ }^{\square}$ email: dagmar.voigt@tu-dresden.de 


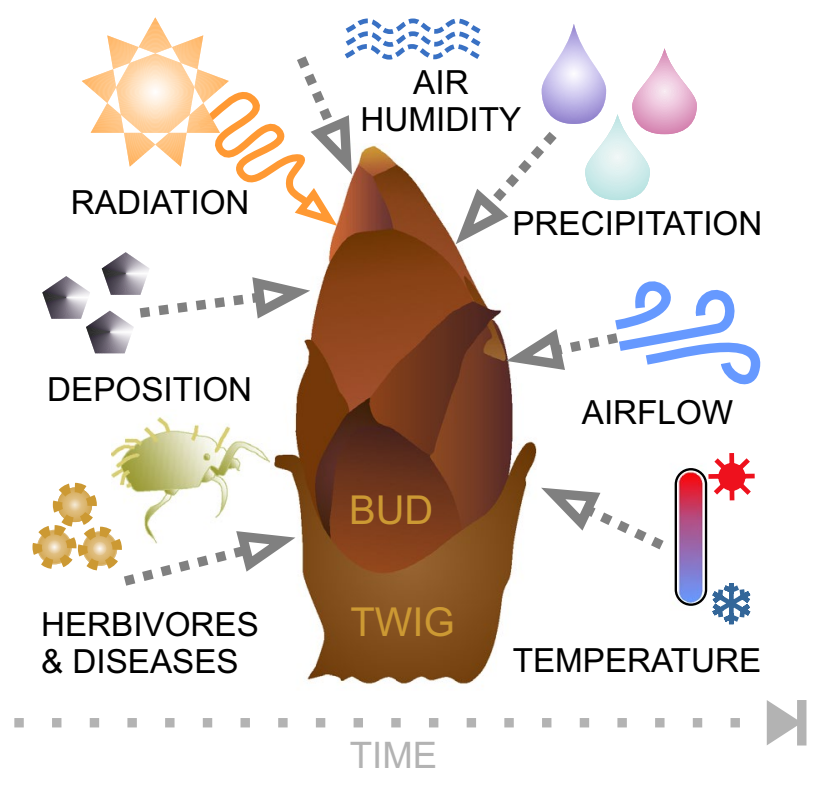

Figure 1. Buds of horse-chestnut trees are exposed to a variety of external abiotic and biotic impacts, such as radiation (UV, IR, etc.), humidity and temperature fluctuations, airflow, rain, snow, hail, particle and aerosol deposition, and phytosanitary risks (microbes, arthropods).

\section{Results}

Appearance. The translucent secretion covered horse-chestnut tree buds (Fig. 2A), forming a relatively homogenous 30-to-50- $\mu \mathrm{m}$ thick superficial layer, and it was also internally present between the bud scales, filling 10-to-150- $\mu \mathrm{m}$ wide spaces between them (Fig. 2B-F). On the glass, it established flat hemispherical droplets (Fig. 2G). The secretion could be pulled into 5-cm long filaments (Fig. 2H,I). In the field, the bud surface mostly looked shiny and non-contaminated, and buds were vital and not damaged (Fig. 2A,B). At times, particles, fibers, or smaller arthropods stuck to the superficial secretion layer (Fig. 2J-L). During rain events, water droplets, if not coalescent, adhered to the bud surface and evaporated later, but never (or seldom) rolled-off.

Freeze-fractured cross-sections elucidated the amorphous nature of the secretion and a variation in thickness of the secretion layers on and between the bud scales (Fig. 3A-G). Cartwheel-shaped micelle-like inclusions of $3.7 \mu \mathrm{m}$ in diameter were randomly found in the secretion without any specific distribution pattern (Fig. 3B,C). The filaments mentioned above could also be observed with cryo-scanning electron microscopy (cryo-SEM), which elucidated extended fibers embedded in a fluid matrix (Fig. 3D). The surface of secretion appeared rather smooth (Fig. 3E). Multicellular glands, about $70-\mu \mathrm{m}$ wide and $50-\mu \mathrm{m}$ high, the spherical colleters, emerged from the bud scale surface and were totally covered with the secretion (Fig. 2E-G). Removal of secretion by washing with ethanol or acetone allowed visualizing the precise position of, however, collapsed colleters (Fig. 3H-K).

Physico-chemical properties. The secretion on the bud remained viscous throughout the whole bud growing season and even after the burst of buds under natural conditions.

The secretion was able to wet all observed substrates, establishing contact angles (CA) that in parts differed significantly from each other (Figs. 2G, 3L-S, 4A,B, Table S1). It spread over the lipoid integument of arthropods, resulting in the lowest $\mathrm{CA}$ of $0^{\circ}$ (Figs. $2 \mathrm{~J}-\mathrm{L}, 3 \mathrm{R}, \mathrm{S}, 4 \mathrm{~A}, \mathrm{~B}$ ). The effect of the substrate did not interfere with that of the secretion condition (two-way analysis of variance, balanced design, substrate $\times$ condition: $F_{3,199}=1.8$, $p=0.057$ ). After being kept in a water-saturated atmosphere, the secretion appeared slightly matt (milky) and swollen, but not dissolved (for swollen aspect see Fig. 3O). At a microscopic level, UV radiation did not cause a distinct change in secretion. Dry heating resulted in a more fluid and elastic state while freezing led to a more plastic behavior, with significantly higher CAs of secretion on glass (Fig. 4A). Single water droplets on the bud maintained a hemispherical shape $\left(\mathrm{CA} 82.5^{\circ} \pm 9.74^{\circ}\right.$, mean $\pm \mathrm{sd}$ ) and did not roll-off when buds were rotated at $180^{\circ}$ at $10 \mathrm{~mm} \mathrm{~s}^{-1}$ (Fig. 4B, Video S1). Oil droplets appeared significantly flatter (CA $54.6^{\circ} \pm 10.21^{\circ} ; t$ test, $t=-6.3$, $p \leq 0.001)$. Both oil and water left distinct circular patterns on secretion after contact.

When the bud secretion was placed on glass slides and stored under different conditions for 7 days, its mass did not change significantly (Fig. 4C, Tables S2, S3). The mass decreased by less than $0.3 \%$ after storage at $22.6^{\circ} \mathrm{C}$, $0.3 \% \mathrm{RH}$, and $22.7^{\circ} \mathrm{C}, 46.6 \% \mathrm{RH}$, and by more than $3.5 \%$ after storage at $50{ }^{\circ} \mathrm{C}, 0.3 \% \mathrm{RH}$. Under a water vaporsaturated atmosphere $\left(22.4^{\circ} \mathrm{C}, 99.3 \% \mathrm{RH}\right)$, the secretion gained $8.2 \%$ in mass, which significantly differed from all other conditions $(p \leq 0.001)$.

The averaged Raman (Fig. 5A) and infrared (IR) (Fig. 5B) spectra obtained for the pure non-treated horsechestnut bud secretion represented a mixture of different biomolecules such as carbohydrates, lipids, and peptides. For this reason, bands appeared rather broad and might be a result of the spectral contribution of several different constituents. Both spectra (Fig. 5) were dominated by the presence of saturated alkanes and fatty 

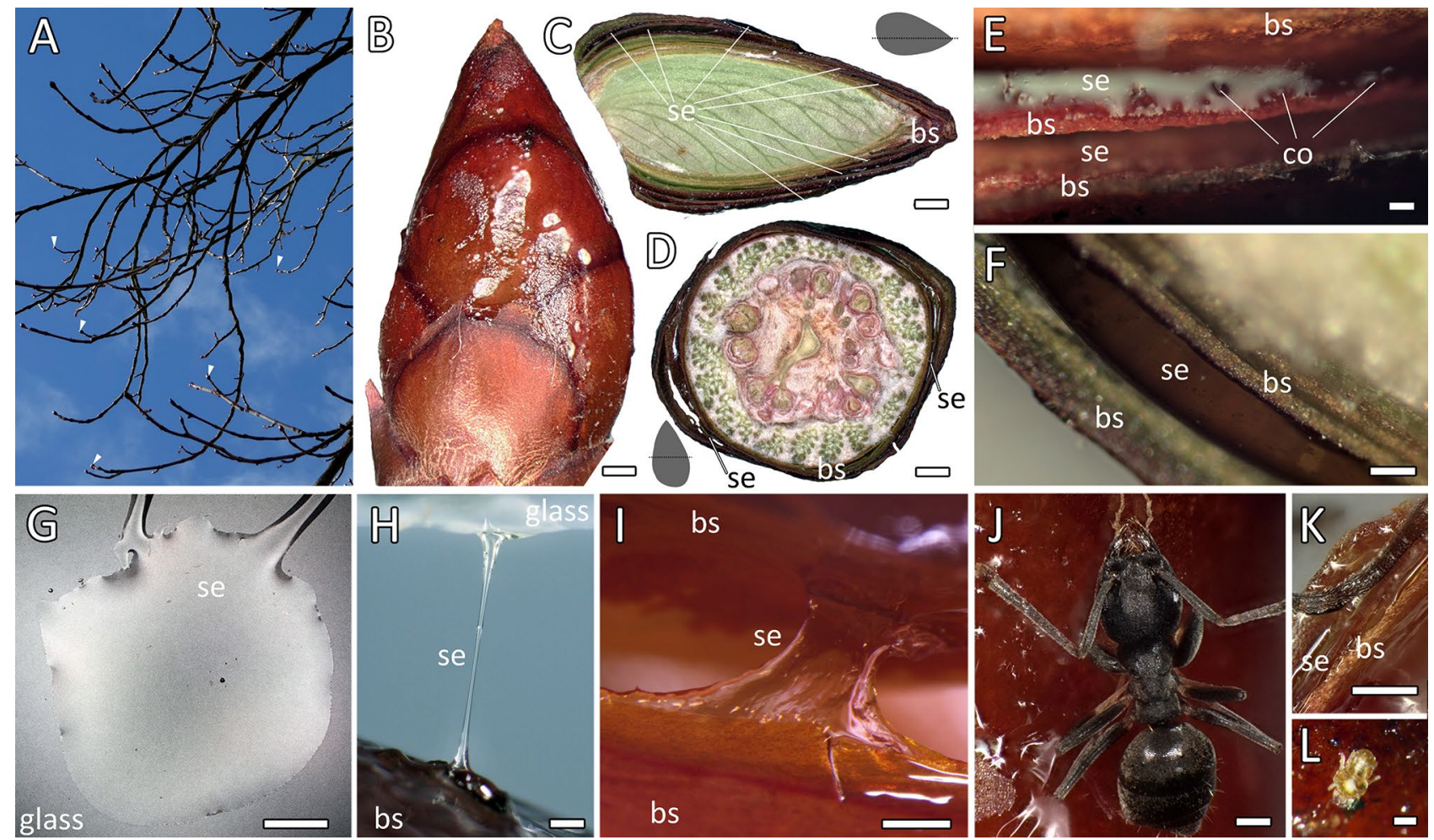

Figure 2. (A) A photograph showing horse-chestnut tree branches and twigs with distally situated, glistening buds (arrowheads). (B-D) Digital microscopic images of the lateral view (B), as well as the longitudinal (C) and transverse (D) cross-sections of the horse-chestnut tree bud. The shiny layer of secretion on the bud surface and between bud scales is clearly visible. (E,F) Details of the secretion embedding the bud scales. The secretionreleasing colleters are indicated in E. (G) Top view of a bud secretion droplet on the normal glass. (H,I) The secretion can be pulled into thin $(\mathbf{H})$ or lamellate filaments $(\mathbf{I})$; (G-I) stereomicroscopic images. (J-L) Digital microscopic images of a white-footed ant adhering to the bud secretion $(\mathbf{J}, \mathbf{K})$ and a mite immobilized by the sticky bud secretion $(\mathbf{L})$. The distal appendages of arthropods are sunken in and covered with the secretion layer. $b s$ bud scale, co colleter, se secretion. Scale bars: (B-D) $1000 \mu \mathrm{m},(\mathbf{E}) 50 \mu \mathrm{m},(\mathbf{F}-\mathbf{H}, \mathbf{J}, \mathbf{K}) 200 \mu \mathrm{m},(\mathbf{I}) 500 \mu \mathrm{m},(\mathbf{L})$ $100 \mu \mathrm{m}$.

acids and showed their characteristic band patterns (band assignment in Supplementary Table S4). Raman spectra of saturated fatty acids were characterized by typical Raman bands at 2935 and $2850 \mathrm{~cm}^{-1}(\mathrm{C}-\mathrm{H}$ asymmetric stretch assigned to $\left.\mathrm{CH}_{2}\right), 1443 \mathrm{~cm}^{-1}\left(\mathrm{CH}_{2}\right.$ bending), and $716 \mathrm{~cm}^{-1}\left(\mathrm{CH}_{2} \text { rocking }\right)^{30}$. The IR spectrum of fatty acids showed bands of the alkyl chain C-H stretching and bending $\left(2930-2800 \mathrm{~cm}^{-1} ; 1457 \mathrm{~cm}^{-1}\right.$ and $\left.721 \mathrm{~cm}^{-1}\right)$ and the carbonyl stretch $\left(1750-1690 \mathrm{~cm}^{-1}\right)$, respectively ${ }^{30}$.

The $\mathrm{C}-\mathrm{H}$ stretching vibration of the cis-double bond $(=\mathrm{C}-\mathrm{H})$, which are typically observed at $3005 \mathrm{~cm}^{-1}$ as well as at $1264 \mathrm{~cm}^{-1}$ (=C-H bending) and $974 \mathrm{~cm}^{-1}$ (out-of-plane $=\mathrm{C}-\mathrm{H}$ bending), were missing, which indicates that non-saturated fatty acids or other non-saturated hydrocarbons were less likely to be present. We observed a band at $1655 \mathrm{~cm}^{-1}$ in both spectra, which could mean a double bond stretching vibration $(\mathrm{C}=\mathrm{C})$, typically occurring at around $1648 \mathrm{~cm}^{-1}$, but, most likely, to be assigned to secondary amides (R-CO-NH- $\mathrm{R}^{30-32}$ ).

The Raman and IR spectra of different fatty acids were very similar and varied only slightly with increasing chain length ${ }^{33,34}$. Saturated fatty acids in the solid-state have defined narrow bands, whereas the bands of shortchain fatty acids in the liquid state appear rather broad ${ }^{33}$. Furthermore, in Raman spectroscopy, spectral ratios are known to be useful to determine the number of $\mathrm{C}=\mathrm{C}$ bonds $\left(1655 / 1444 \mathrm{~cm}^{-1}\right.$ ratio $\left.^{33,35}\right)$ of the fatty acid chain length (e.g., the ratio between $\left.2850 / 2935 \mathrm{~cm}^{-1}\right)^{34}$. Taking all this into account, we suspect a rather short $\left(<\mathrm{C}_{12}\right)$ fatty acid in the liquid state. If matched to a spectral database, the spectra showed a high resemblance to saturated fatty acids $<\mathrm{C}_{10}$, especially to the straight-chain saturated nonanoic (= pelargonic) acid $\left(\mathrm{C}_{9} \mathrm{H}_{18} \mathrm{O}_{2}\right)$. This assumption was further confirmed by the Raman band intensity ratio $2850 / 2935 \mathrm{~cm}^{-1}$, which results in a value corresponding to $\mathrm{C}_{9}{ }^{34}$.

In addition to Raman, the IR spectrum showed two characteristic bands at 1731 and $1706 \mathrm{~cm}^{-1}$ in the region of the carbonyl absorption $\left(\mathrm{C}=\mathrm{O}, 1750-1690 \mathrm{~cm}^{-1}\right)$, indicating the presence of both esters and free carboxylic acids.

A careful examination of IR and Raman spectra revealed some significant minor components. A weak band at $3070 \mathrm{~cm}^{-1}$ (C-H aromatic stretch) indicated the presence of an aromatic compound, which was supported by the IR band at $1594 \mathrm{~cm}^{-1}$ and the Raman band at $1614 \mathrm{~cm}^{-1}$ that characterize $\mathrm{C}=\mathrm{C}$ aromatic skeletal vibrations.

A supplementary high resolution nuclear magnetic resonance (HR NMR) spectroscopy study supported the Raman and IR findings by ${ }^{1} \mathrm{H}$ and ${ }^{13} \mathrm{C}$ NMR data (see Fig. S1 for method and data). Both NMR spectra were dominated by aliphatic signals $\left(\mathrm{CH}_{2} / \mathrm{CH}_{3}\right)$ and show contributions of carboxylic acids and esters. This result is in good agreement with saturated alkanes, fatty acids, and esters being the main components. Typical chemical shifts 

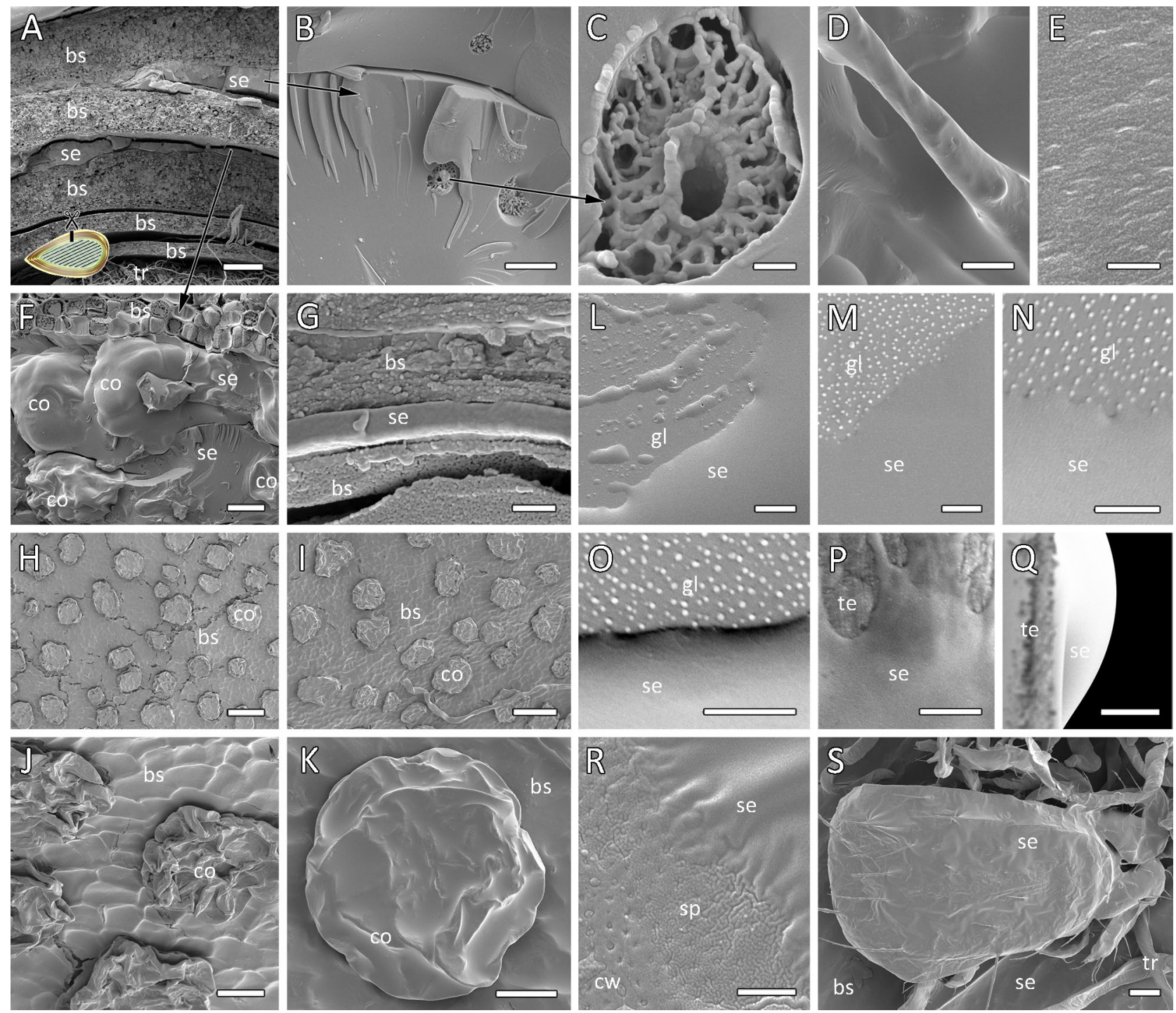

Figure 3. Cryo-SEM images of the horse-chestnut bud scales and secretion. (A) Cross-section (freeze-fracture) of bud scales and embedded secretion. The inset indicates the fracture position on the bud. See the close-up views in (F) and (G). (B-E) Details of the bud secretion cross-section after freeze-fracture (B,C), pulled into a filament indicating a fibrous component (D), and the non-structured surface (top view in $\mathbf{E}$ ). Note the presence of micelle-shaped structures included in the amorphous layer of secretion $(\mathbf{B}, \mathbf{C})$. (F,G) Freeze fracture of bud scales and secretion covering the secretion-releasing colleters. $(\mathbf{H}-\mathbf{K})$ Solvent treatments: the bud scale surface covered with numerous collapsed colleters after washing with acetone and total removal of secretion $(\mathbf{H}, \mathbf{I})$, partially collapsed colleters after washing with ethanol leaving residues of secretion $(\mathbf{J}, \mathbf{K})$. (L-O) The interface of bud secretion droplets and normal glass, after keeping the secretion at $22.7^{\circ} \mathrm{C}, 46.6 \% \mathrm{RH}(\mathbf{H}, \mathbf{I})$, at $22.6{ }^{\circ} \mathrm{C}$, $0.3 \% \mathrm{RH}(\mathbf{J})$, and at $22.4^{\circ} \mathrm{C}, 99.3 \% \mathrm{RH}(\mathbf{M}) .(\mathbf{P}, \mathbf{Q})$ The secretion droplet in contact with Teflon tape, top (P) and side view $(\mathbf{Q})$. (R) The interface between the bud secretion and a cockroach forewing showing a wrinkled, self-organized pattern at the edge. (S) A mite stuck to the bud, having the integument partially covered with bud secretion and distal legs entangled with secretion and trichomes. $b s$ bud scale, $c o$ colleters, $c w$ female cockroach forewing, $g l$ glass, $s e$ secretion, $s p$ self-organized pattern, te teflon, $t r$ trichomes. Scale bars: (A) $200 \mu \mathrm{m} ;(\mathbf{B}, \mathbf{D}, \mathbf{L})$ $5 \mu \mathrm{m} ;(\mathbf{C , E}, \mathbf{G}, \mathbf{M}, \mathbf{N}, \mathbf{O}, \mathbf{P}) 500 \mathrm{~nm} ;(\mathbf{F}, \mathbf{I}, \mathbf{J}, \mathbf{K}, \mathbf{S}) 20 \mu \mathrm{m} ;(\mathbf{H}, \mathbf{Q}) 100 \mu \mathrm{m} ;(\mathbf{R}) 2 \mu \mathrm{m}$.

for the $\mathrm{N}-\mathrm{H} / \mathrm{H}_{\alpha}$ protons and the $\mathrm{C}_{\alpha}$ positions in secondary amides were also observed but in minor amounts. In the NMR spectra, signals of weak intensity were found in the aromatic region, supporting the presence of a minor aromatic compound. Compared to the aliphatic signals, the other regions (carboxylic groups, non-saturated/ aromatic, amides) make up less than $2 \%$ of the integral intensity of the ${ }^{1} \mathrm{H}$ NMR spectrum.

Adhesion. The pull-off force experiments proved that the horse-chestnut bud secretion is an adhesive (Fig. 6, Table S5, Video S2), which maintained its properties after 100 repeated trials (Fig. 6C), demonstrating the force ranging from 48.5 to $85 \mathrm{mN}(64-78 \mathrm{kPa})$. The shape of obtained force-time curves indicated an abrupt loss of adhesion despite extended secretion filaments (Fig. 6A), which required a low work to be separated 


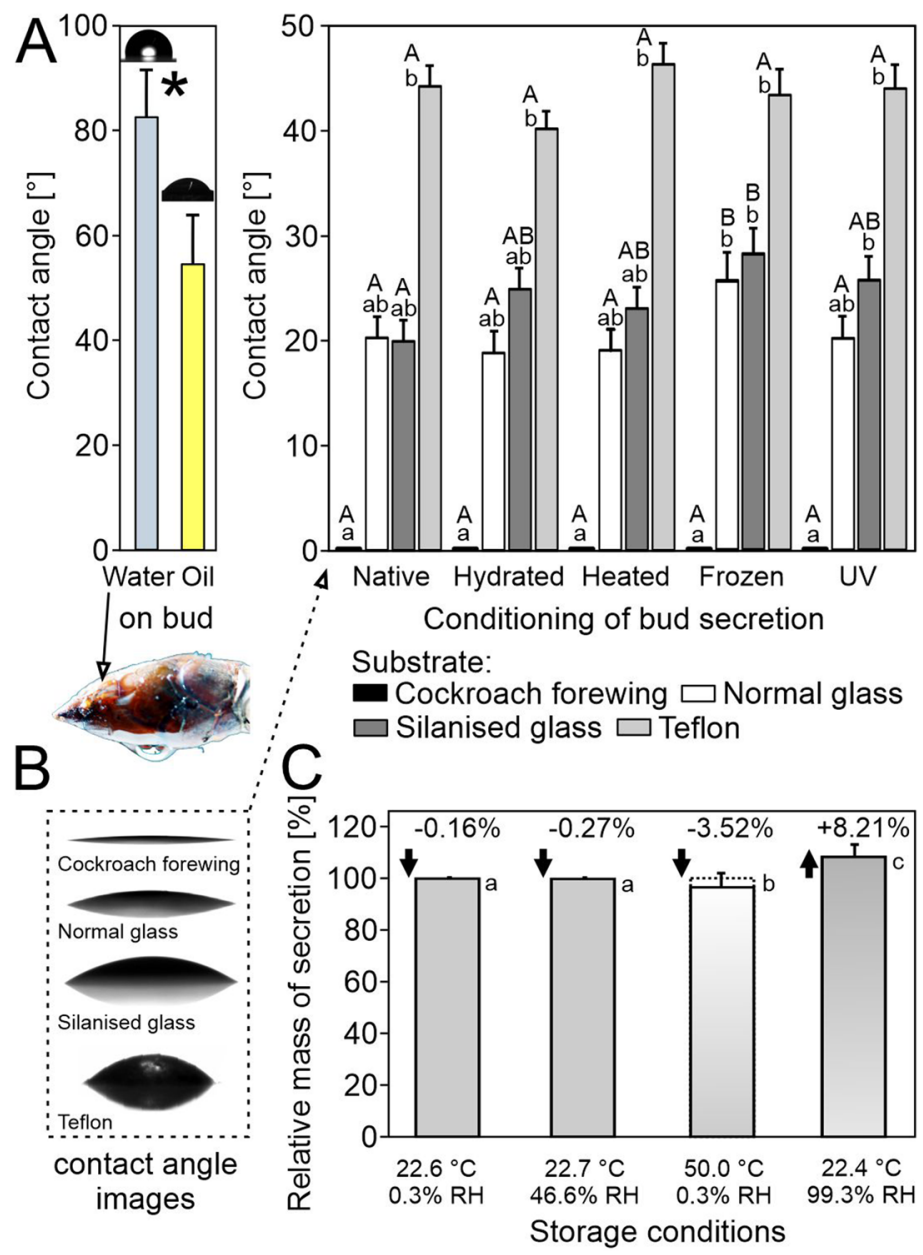

Figure 4. (A) Sessile contact angles of differently conditioned bud secretion droplets on various substrates, as well as of water and oil droplets on a native alive bud. Different small letters indicate statistical differences between substrates for the same conditioning, capital letters between conditioning for the same substrate (twoway analysis of variance, balanced design, followed by all pairwise multiple comparison procedures Tukey test, $p=0.05$; substrate: $F_{3,199}=653.3, p<0.001$; condition: $F_{3,199}=4.3, p=0.002$; substrate and secretion conditioning did not exert interactive effects: substrate $\times$ condition: $\left.F_{3,199}=1.8, p=0.057\right)$. The asterisk corresponds to the statistical difference between the water and oil contact angles on bud: $t$ test, $t=-6.3, p \leq 0.001$ ( $\mathrm{n}=10$ per fluid). (B) Images of the bud secretion droplets on different substrates and a bud with an abaxially adhering droplet of water. (C) Relative change of the bud secretion mass on the normal glass after 7-day storage at different conditions. No significant differences in mass before and after storage for the same condition were detected (Table S3). Different small letters indicate statistic differences between treatments (Kruskal-Wallis one-way ANOVA on ranks, $H_{3,98}=80.1, p \leq 0.001$, followed by all pairwise multiple comparison procedures Tukey Test, $p<0.05)$.

(Fig. 6B). The pull-off force significantly increased with increasing pull-off speed (nonlinear regression, NR, $R^{2}=0.99, p=0.0002$; Fig. $6 \mathrm{D}$ ) and increasing preload (NR, $R^{2}=0.97, p=0.0002$; Fig. $6 \mathrm{E}$ ), ranging between 13 and $167.5 \mathrm{mN}$. The secretion layer thickness at $10-\mathrm{mN}$ preloaded condition was $9.0 \pm 2.50 \mu \mathrm{m}(\mathrm{n}=50)$. At the highest speed and preload $\left(80 \mathrm{mN}, 320 \mu \mathrm{m} \mathrm{s}^{-1}\right)$, the pull-off force was $185.7 \pm 17.92 \mathrm{mN}(\mathrm{n}=10)$, corresponding to an adhesive strength of $204.3 \mathrm{kPa}$.

The pull-off force did not significantly differ between substrates (Fig. $6 \mathrm{~F}$ ). The adhesive strength was statistically two times lower on cockroach forewings compared to Teflon and glass: $34.6 \pm 13.65 \mathrm{kPa}, 55.2 \pm 15.71 \mathrm{kPa}$, and $68.2 \pm 21.03 \mathrm{kPa}$, respectively (one-way ANOVA followed by all pairwise multiple comparison procedures Tukey test, $F_{2,29}=9.5, p<0.001$ ). However, it did not depend on the secretion contact angle on a substrate (linear regression, $\mathrm{LR}, R^{2}=0.07, p=0.6$; Fig. S2). After hydration, the pull-off force was significantly lower than that one of the frozen samples $\left(F_{4,49}=2.6, p=0.046\right)$; the forces of other conditioned samples did not differ from each other. The adhesive strength was significantly lower for UV-treated samples $(57.0 \pm 15.35 \mathrm{kPa})$ compared to frozen ones $(86.5 \pm 23.23 \mathrm{kPa})$, while it did not differ between the other samples $\left(F_{2,29}=3.9, p=0.008\right)$. The data set did not fit to a two-way analysis of variance and general linear model. That is why one-way ANOVA separately evaluated the groups. 

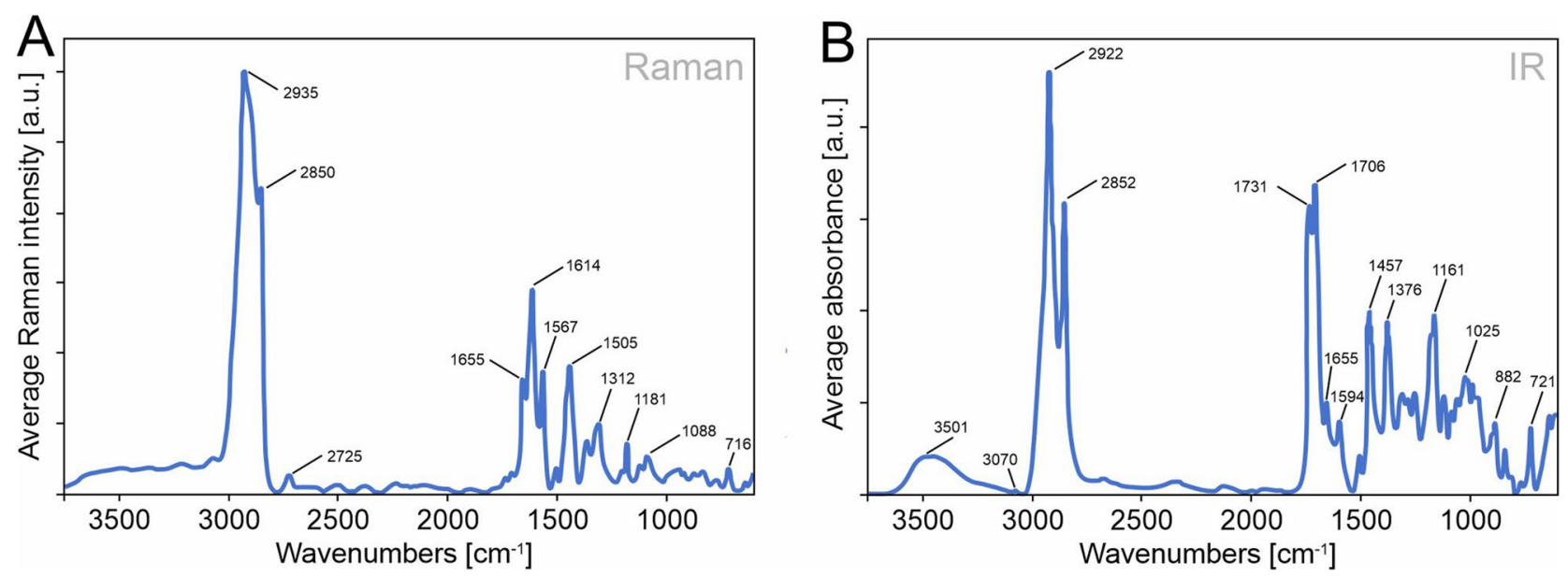

Figure 5. Chemical composition of the natural horse-chestnut tree bud secretion. (A) Raman spectrum and (B) ATR FTIR spectrum. Both spectra show spectral bands characteristic to $\mathrm{OH} / \mathrm{NH}, \mathrm{CH}_{2}, \mathrm{C}=\mathrm{O}$ (ester and acid), and amide $(\mathrm{C}=\mathrm{O}-\mathrm{NH})$ groups and thus, the presence of long-chain, saturated alkanes, fatty acids, and esters, as well as amides.

Low vacuum SEM confirmed that the pull-off forces were detected at the first rupture of secretion that happened at about $20 \mu \mathrm{m}$ displacement. Correspondingly, the fibrous nature of secretion was most prominent during the initial stages of the experiment. Further extension of filaments did not result in measurable forces and appeared as a certain flow in liquified filaments. Fast pull-off speed $\left(>100 \mu \mathrm{m} \mathrm{s}^{-1}\right)$, lower secretion volume, heating, and hydration of samples caused extension of single long thin filaments (Fig. S4), while slower pull-off speed, freezing, and UV radiation of samples mostly implicated establishment of lamella-shaped or multifilamentous bulks of secretion (Fig. S5). Such structures frequently showed increasing cavitation with increasing displacement. After thinning, filaments separated at their middle, and the torn ends formed hookshaped residues that snapped back to the substrate recovery droplet. Except for cockroach wings, a smaller portion of secretion adhered to the counter surface, while the larger one remained on the substrate where the sample was initially placed (Video S6). By ocular observation, frozen samples appeared to be more plastic than elastic, and they were heavier to separate. After storage at $50{ }^{\circ} \mathrm{C}$ and $0.3 \% \mathrm{RH}$, samples were smeary and pullable into very long thin filaments, which separated faster than those of non-treated secretion (Videos S3, S4). Hydrated secretion was more compressible and extendable into thin filaments, which snapped fast back after separation (Video S4).

\section{Discussion}

Structure-function relationships of the horse-chestnut bud secretion. The results observed in our study explain well why the sticky secretion impregnates and protects horse-chestnut buds over a long period while resisting a variety of environmental impacts (Fig. 1). The secretion does not dry out under arid conditions, does not melt at $50{ }^{\circ} \mathrm{C}$, and does not change significantly under UV radiation or frost at the microscopic level. It is swellable to a certain degree underwater and in a humid atmosphere, and it universally wets substrates having different polarities and textures. Such stability over a wide range of environmental conditions is achieved by a three-dimensional polymeric network ${ }^{36}$, e.g., in plant resins. The latter predominantly occur in woody seed plants, being primarily lipid-soluble mixtures of volatile and nonvolatile terpenoid and/or phenolic secondary compounds ${ }^{27,37}$. However, the horse-chestnut bud secretion here is a multi-component material, including saturated alkanes, fatty acids, and esters, as well as polyamides, which are embedded in a fluid matrix of fatty acids/alkanes comprising nonpolar and polar portions. Low-esterified polyamides are reported to be nondegradable ${ }^{38}$ and to ensure high thermal stability and excellent chemical resistance to solvents, plasticizers, and oils, as well as higher mechanical flexibility on glued junctions, compared to other hot melt adhesives ${ }^{39}$.

Raman, IR, and NMR spectroscopy of pure bud secretion confirmed the presence of saturated alkanes, fatty acids, and fatty acid esters (most likely with a chain length $<\mathrm{C}_{12}$ ), as well as amide and aromatic constituents. Saturation explains low chemical reactivity, relatively stable consistency, and translucent appearance of bud secretion, as also previously observed by Wollenweber ${ }^{24}$.

Reversible changes in the secretion material properties due to UV radiation, heating, and freezing also underpin the saturated nature of secretion, which does not further polymerize or loose cross-links. At the micro and nanoscale, the bud secretion looks amorphous, well mixed, and not structured despite several micelle-shaped inclusions (Fig. 3B,C). Micelles are known to clump immiscible parts of different molecules together, increasing the miscibility and wettability of fluids ${ }^{40}$. Such emulsion of fluids was observed for both oil and water droplets, which left distinct circular patterns on secretion after contact. This fact refers to the biphasic composition of the bud secretion, including lipophilic (fatty) and hydrophilic (amide, ester) portions, as well as polar and nonpolar interactions in fatty acid molecules (Fig. 5A) ${ }^{30,41}$.

Based on the above results, saturated alkanes, free fatty acids, and fatty acid esters are the main components of the bud secretion. Fatty acids may be cross-linked and functionalized by autoxidation, polymerization, hydrogenation, hydroaminomethylation, ozonolysis, methoxycarbonylation, or polycondensation of functional 

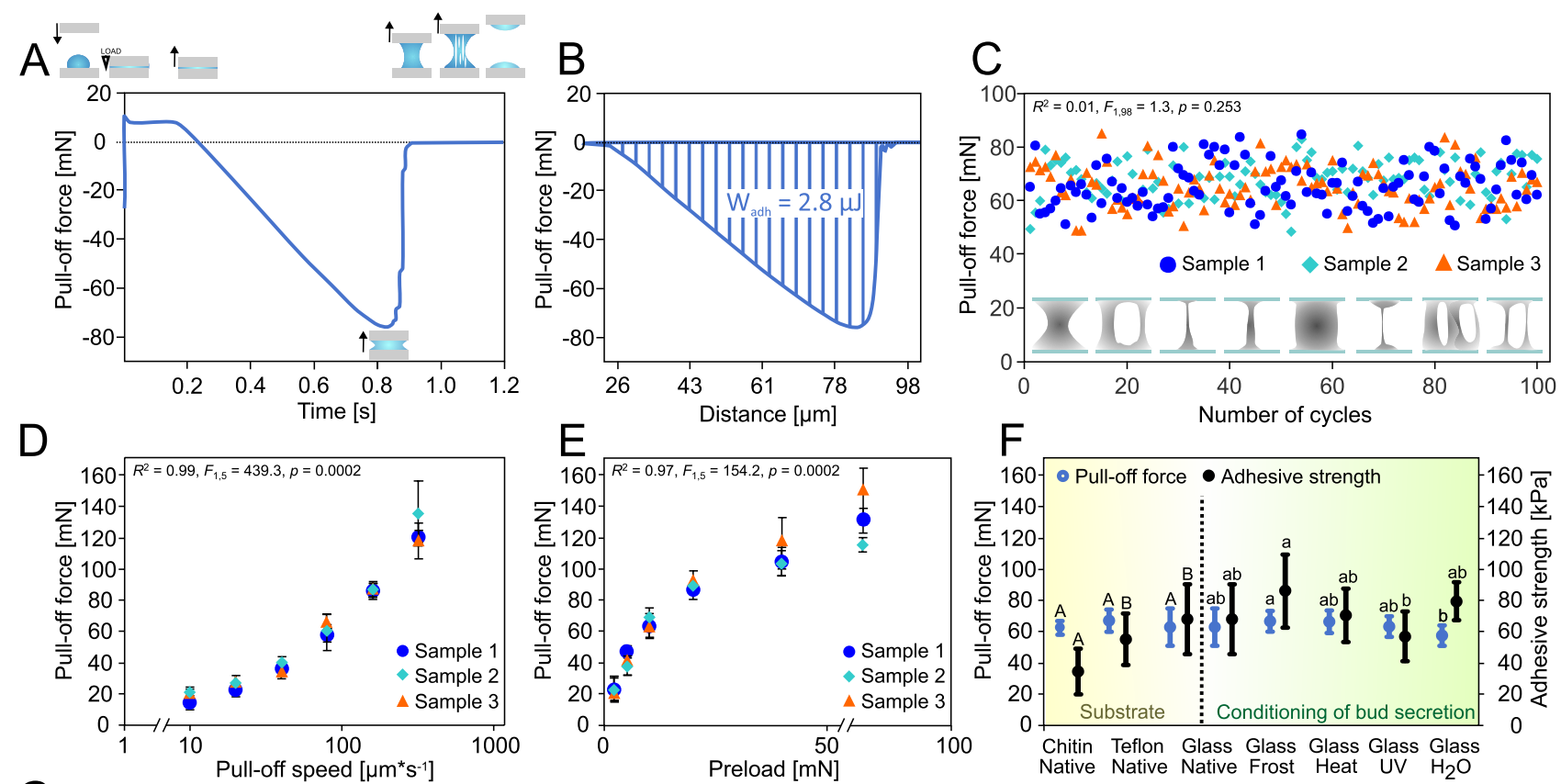

G

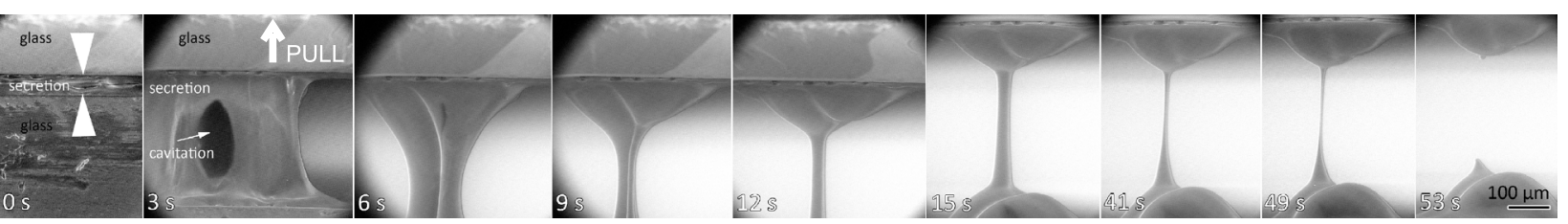

Figure 6. Adhesive properties of the viscous secretion released from buds of horse-chestnut trees. (A) An example of force-time curves obtained during pull-off force experiments with secretion placed between glass slides. The insets indicate the experimental design and measurement procedure. (B) A representative force-distance curve transformed from force-time data in A, displaying the work needed to separate the bud secretion between two glass slides at a distance of $50 \mu \mathrm{m}$. Note that also the work needed to deform the force sensor is included in this two-component measure. (C) Reliability of bud secretion investigated by a series of 100 repeated pull-off tests with the same sample $(n=3)$. Force did not decrease with the increasing number of cycles ( $\left.\mathrm{LR}, R^{2}=0.01\right)$. The inset illustrates different shapes of pulled filaments of secretion observed during the experiments. (D) Pull-off force measured as a function of pull-off speed (means and error bars, $\mathrm{n}=3$ ), showing a positive relationship (NR, $\left.R^{2}=0.82\right)$. (E) Pull-off force measured as a function of preload (means and error bars, $\mathrm{n}=3$ ), showing a positive relationship $\left(\mathrm{NR}, R^{2}=0.48\right)$. (F) Pull-off forces and adhesive strength measured on three substrates (chitinous forewing of a female American cockroach, Teflon: polytetrafluorethylene, normal glass) and with five differently conditioned secretion samples on normal glass after keeping 5 days non-treated, frozen, heated, UV-radiated, or hydrated (means and error bars). Capitals indicate statistical differences in force or adhesive strength values between substrates; lower letters indicate statistical differences in force or adhesive strength values between secretion conditions: one-way ANOVA followed by all pairwise multiple comparison procedures Tukey test, $p=0.05$; pull-off force @ condition: $F_{4,49}=2.6, p=0.046$; pull-off force @ substrate $F_{2,69}=1.1, p=0.363$; adhesive strength @ condition $F_{2,29}=3.9, p=0.008$, adhesive strength @ substrate $F_{2,29}=9.5$, $p<0.001$. (G) Low vacuum SEM images showing an example of pulled-off secretion within $53 \mathrm{~s}$.

monomers to polyesters ${ }^{42,43}$. The latter fits well with the above-mentioned nonanoic acid. Altogether, one may hypothesize an aliphatic hydrocarbon resin or oligoester to describe the complex mixture of horse-chestnut bud secretion.

In accordance with previous reports for acetone extracts of entire buds, spectroscopy in the present study provides hints for the presence of a minor aromatic compound, e.g., flavonol aglycones or rather terpenoids in the pure bud secretion ${ }^{24,28,44}$. Also, the recent GC-MS study with hexane extract of entire buds reporting alkanes, phenolic acid/ester, tetradecanal $\left(\mathrm{C}_{14} \mathrm{H}_{28} \mathrm{O}\right)$, and saturated tetradecanoic acid $\left(\mathrm{C}_{14} \mathrm{H}_{26} \mathrm{O}_{4}\right)^{28}$ is supported to some extent by our analysis. A certain discrepancy between the results of previous and recent studies could be explained by different sampling and the inherently limited spectral resolution of Raman and IR spectroscopies due to the superimposition of spectral information from different compounds. According to Wollenweber and $\mathrm{Jay}^{45}$, lipophilic flavonoids co-occur with sesqui- or triterpenes in plant exudates. Terpenoids are frequently released from plant glandular trichomes, such as horse-chestnut bud colleters ${ }^{27,43}$, and should be included in sticky secretions resulting in instant tack, such as observed for horse-chestnut buds. 
Adhesion of the horse-chestnut bud secretion. The composition of the visco-elastic bud secretion resembles that of pressure-sensitive adhesives (PSA) consisting of the multi-component multiphase mixture of backing hydrocarbon resin and fatty acid esters, tackifying terpenes, and surfactant fatty acids, having about $50-70 \%$ of an insoluble fraction ${ }^{46-48}$. Bud secretion and commercial PSA share specific properties, such as a universal wetting of substrates mediating sufficient instantaneous contact formation (tack) and a four-step debon-ding process including deformation, cavitation, fibrillation, and rupture ${ }^{47-50}$. The bud secretion in contact spread over the substrate establishing flat layers under tension (CA of less than $30^{\circ}$ and $50^{\circ}$ on glass and Teflon, respectively). According to Chalykh and Shcherbina ${ }^{51}$, these adhesive-substrate transition zones matter in adhesive joints because they may spontaneously form emulsions of one polymer within the other polymer, creating a thermodynamic and colloid chemical interface boundary. Such a boundary was particularly observed for bud secretion on the lipoid integument of arthropods $\left(\mathrm{CA}\right.$ of $0^{\circ}$ ), interacting with the epicuticular greasy layer, creating self-organized patterns (Fig. 3R) and a larger contact area compared to that on the other substrates (Table S5). We suggest interactive forces, which are established between the atoms and molecules at the interface of the bud secretion and substrate, fitting to the adsorption theory of material adhesion ${ }^{48}$.

As reported for PSA e.g., ${ }^{52}$, the link formed between the substrate and the bud secretion adhesive layer further depends on the time of contact and the force applied during the bonding stage (Fig. 6D,E).

Both surface (free surface energy, roughness, etc.) and bulk properties of the adhesive are known to govern the nature and location of fracture ${ }^{49,53}$. Similar to technical PSAs, the natural bud secretion is a viscoelastic material that deforms under debonding force, forming cavitation bubbles and filaments of up to 5-cm long, which evince inner flow under tension (Figs. 2H,I, 3D; Videos S3-S6). Initially, cavities form on defects or trapped air at the substrate-adhesive interface when tension stress is applied. The principal role of these cavities in PSAs has been previously assigned to the reduction of local stresses and the prevention of any large stress concentrations towards the avoidance of fracture ${ }^{54}$. If the cavities grow laterally and vertically, they fuse and form cracks, causing rapid interfacial debonding. If the coalescence of adjacent cavities does not occur, the walls between them are extended as fibrils through the growth of interfacial crack propagation. The extension of single long thin filaments was mainly observed for high pull-off speed $\left(>100 \mu \mathrm{m} \mathrm{s}^{-1}\right)$, low bud secretion volume, as well as heated and hydrated samples. Low pull-off speed, freezing, and UV radiation mostly resulted in lamellar or multifilamentous shapes of deformed bud secretion. After thinning, pulled filaments separated in the middle. The torn ends bent hookshaped before they snapped back to the substrate and recovered to droplets. A typical cohesive debonding was observed, where some residues of adhesive are left on the probe at the end of the test ${ }^{55}$. A smaller portion of bud secretion adhered to the counter surface, while the larger one remained on the substrate where the sample was initially placed, except for lipoid cockroach wings, to which a larger residue stuck. In addition, the force-time curves obtained for bud secretion showed an abrupt decrease of adhesion despite extended secretion filaments. For PSAs, such a curve shape has been explained by the process of cavity growth in a rubbery elastic medium, which is commonly indicative of weak adhesion and interfacial crack propagation ${ }^{47,54}$.

As demonstrated by the consistent adhesion during 100 repeated cycles of pull-off tests, the horse-chestnut bud secretion is persistent even after cavitation, filament extension, and rupture. Such recoverable adhesive joints are mainly attributed to molecular interactions (e.g., friction between molecules ${ }^{56}$ ), rather than tight crosslinks between polymer chains. The latter would avoid flow, solubility, and are commonly irreversibly broken upon rupture ${ }^{47}$. The recovery of bud secretion is confirmed by heat, frost, water, and UV treatments, which led to only slight changes in consistency and adhesion of secretion at the microscopic level. However, stronger intermolecular interactions are expected in frozen samples, which appear to be more plastic than elastic.

The adhesive strength was significantly higher in frozen samples compared to UV-treated ones, while it did not differ between the other samples. Thus, one may assume different effects of frost and UV radiation on bud secretion, while the latter is known for the initiation of curing by radical polymerization ${ }^{55}$. The storage at $50{ }^{\circ} \mathrm{C}$ and $0.3 \%$ RH loosened the bud secretion network in such a manner that samples were smeary, obviously more fluent, and pullable into very long thin filaments, which separated faster than those of non-treated secretion. Hydrated secretion appeared slightly milky, more compressible, and extendable into thin filaments, which snapped back fast after separation; the pull-off force was significantly lower than that obtained with the frosttreated samples. Such effects have been previously discussed for the sticky, resinous secretion of carnivorous dew plants Roridula gorgonias Planch. (Roridulaceae): the underwater changes were attributed to the polar compounds in secretion and ion interaction, causing swelling of resins and elastic materials ${ }^{57-59}$. Interestingly, the horse-chestnut bud secretion adhered to glass also underwater without a significant difference to maximum pull-off forces in air, reaching an average of $15.4 \mathrm{mN}$ and $12.4 \mathrm{mN}$, respectively, as shown by a preliminary experiment (Fig. S3).

Commercial PSAs seem to stick more strongly than plant secretion at a comparable adhesive layer thickness. For example, probe tack tests with the standard PSA poly(2-ethyl hexyl acrylate), including $2 \%$ acrylic acid (PEHA-AA), resulted in a debonding strength of $1.3 \mathrm{MPa}$ at a $1 \mathrm{~mm} \mathrm{~s}^{-1}$ separation rate, a $0.07-0.1 \mathrm{~mm}$ adhesive layer thickness, and $900 \mathrm{kPa}$ applied contact pressure ${ }^{60}$. The maximum adhesive strength in horse-chestnut bud secretion $(204 \mathrm{kPa}$ ) is higher than that of sticky leaf coverage in tarflowers Befaria racemosa Venten (Ericaceae) and commercial flypaper Tanglefoot $(40-50 \mathrm{kPa})^{61}$. It resembles those obtained for pressure-sensitive adhesive secretion in dew plants $R$. gorgonias and radiator plants Peperomia polystachya (Ait.) Hook. (Piperaceae) on normal glass: $200 \mathrm{kPa}$ and $155 \mathrm{kPa}$, respectively. Note that the applied contact pressure ( $\mathrm{kPa})$, layer thickness $(\mu \mathrm{m})$, and pulling velocity $\left(\mu \mathrm{m} \mathrm{s}^{-1}\right)$ differed in previous and present experiments (B. racemosa: $4-9 \mathrm{kPa}, 1300 \mu \mathrm{m}$, $500 \mu \mathrm{m} \mathrm{s}^{-1}$; R. gorgonias: $1.9 \mathrm{kPa}, 130 \mu \mathrm{m}, 2300 \mu \mathrm{m} \mathrm{s}^{-1}$; A. hippocastanum: $\left.88 \mathrm{kPa}, 9 \mu \mathrm{m}, 100 \mu \mathrm{m} \mathrm{s}^{-1}\right)$. Also, dew and radiator plant secretions comprise a mixture of resins based on aliphatic esters and carboxylic acids; their FTIR spectra are comparable to that of synthetic ethylene-vinyl acetate ${ }^{62}$. The presence of minor amounts of amide groups in concert with fatty acids in horse-chestnut bud secretion differs from other PSAs in distantly 
related plant species. This smart blend of multiple compounds add to the plant fitness and energy efficiency by supplying the buds of the ancient eudicot $A$. hippocastanum ${ }^{63}$ with a long-term persistent protective adhesive layer, having universal reliability and applicability under a wide range of impacts. How far similar effects are found in the bud secretion of other plant species remains an exciting question to be answered in future comparative studies. Also, the detailed structural chemistry and changes of bud secretion under various conditions at the molecular level need further clarification.

In the context of bio-inspired adhesion, this composition may find use in developing novel amide groupcontaining commercial resins to improve existing photostable polyisocyanate resins widely used for varnishes ${ }^{64}$, acrylate PSA used for drug delivery via hydrogen bond-forming ability ${ }^{65}$, functionalized biodegradable polymers $^{66}$, and polyamide hot melt adhesives applied in the automotive, textile and electronic industries ${ }^{39}$.

\section{Conclusion}

The secretion of horse-chestnut buds is a persistent, reliable, reversible, and universal PSA able to withstand numerous abiotic and biotic environmental impacts (Fig. 1). The integration of viscid and other properties, such as non-degradability, protection against water loss and high/low temperatures, is of great interest to the development of multifunctional biomimetic adhesives.

Elucidating the elemental chemical composition and adhesive properties of horse-chestnut bud secretion, our study adds to the comprehensive understanding of the diversity of adhesive plant secretions, shedding light on particular structure-function relationships. The bud secretion robustness matters for coevolutionary and ecological interactions and provides a living example for bio-inspired innovations in commercial PSA.

\section{Materials and methods}

Plant material. Fresh buds of Aesculus hippocastanum L. (Sapindaceae) were collected from about 30-yearold trees growing at ruderal sites in Dresden, Germany $\left(51^{\circ} 1^{\prime} 30^{\prime \prime} \mathrm{N}, 13^{\circ} 43^{\prime} 59^{\prime \prime} \mathrm{E}\right)$ and kept turgescent during the study.

Substrates. Prior to experiments, soda-lime glass microscope slides $(76 \times 26 \mathrm{~mm})$ and 5-mm diameter circular coverslips (Gerhard Menzel B.V. \& Co. KG, Braunschweig, Germany) were cleaned by immersion in Piranha solution (a mixture of sulphuric acid $\mathrm{H}_{2} \mathrm{SO}_{4}$ and hydrogen peroxide $\mathrm{H}_{2} \mathrm{O}_{2}, 3: 1$ ), repeatedly rinsed with Aqua Millipore water and dried immediately using compressed air. Silanized object slides (Silane-Prep glass slides coated with aminoalkyl silane, Sigma-Aldrich, Saint Louis, MO, USA) and Teflon (chemical-resistant slippery PTFE Sheet, McMaster-Carr, Douglasville, GA, USA, polished, Ra 40 nm) were used as supplied.

Female American cockroaches Periplaneta americana L. (Blattodea, Blattidae) were collected in a private property in Atlanta (GA, US; $33^{\circ} 45^{\prime} 58^{\prime \prime} \mathrm{N}, 84^{\circ} 22^{\prime} 19^{\prime \prime} \mathrm{W}$ ) and anesthetized by freezing before cutting off their forewings using scissors. Cockroaches were selected as model arthropods because of their well-known antiadhesive greasy lipid slough-off layer on the integument surface ${ }^{67}$ and large flat wings that can be utilized as sample surfaces.

Microscopy. Secretion-covered buds were imaged with (i) a stereomicroscope Olympus SZX16 combined with objectives Olympus SDF Plapo $1.6 \times$ PF and $0.5 \times$ PF, the camera Olympus DP26, and the cellSens Standard software (Olympus Corp., Tokyo, Japan) ${ }^{68}$, (ii) the Keyence digital microscope VHX970F (Keyence Corp., Osaka, Japan), and (iii) the cryo-scanning electron microscope (cryo-SEM) SUPRA 40VP-31-79 (Carl Zeiss SMT Ltd., Oberkochen, Germany) equipped with an EMITECH K250X cryo-preparation unit (Quorum Technologies Ltd., Ashford, Kent, UK) following Bräuer et al. ${ }^{68}$. For cryo-SEM, pieces of bud scales were cut with a razor blade and mounted on metal stubs using polyvinyl alcohol (Tissue-Tek, OCT, Sakura Finetek Europe BV, Alphen aan den Rijn, the Netherlands). Subsequently, the samples were shock-frozen in liquid nitrogen in the slushing chamber, transferred to the cryo-preparation chamber at $-140{ }^{\circ} \mathrm{C}$, sublimed for $30 \mathrm{~min}$ at $-70{ }^{\circ} \mathrm{C}$, sputtercoated with platinum (layer thickness ca. $6 \mathrm{~nm}$ ), transferred to the SEM, and then examined in a frozen state at $5 \mathrm{kV}$ accelerating voltage and $-100^{\circ} \mathrm{C}$ temperature. Cryo-SEM micrographs were taken using the software Smart SEM 05.03.05 (Carl Zeiss SMT Ltd., Oberkochen, Germany). Metric characteristics were determined from the obtained micrographs using the SigmaScan Pro 5.0.0 software (SPSS Inc.).

Weighing. Secretion droplets were weighed with the Excellence balance XA 205 Dualrange (Mettler Toledo $\mathrm{GmbH}$, Greifensee, Switzerland) to quantify (1) the mass of secretion used for pull-off force tests and contact angle measurements, and (2) the loss or increase of the mass of secretion after the storage under different conditions. For the latter, secretion droplets on clean glass slides were kept for 7 days under different conditions: (i) $22.7 \pm 0.87^{\circ} \mathrm{C}$ and $46.6 \pm 3.35 \% \mathrm{RH}$, (ii) $22.4 \pm 0.19^{\circ} \mathrm{C}$ and $99.3 \pm 1.72 \% \mathrm{RH}$, (iii) $22.6 \pm 0.22{ }^{\circ} \mathrm{C}$ and $0.3 \pm 0.34 \%$ $\mathrm{RH}$, (iv) $50.0 \pm 0.09^{\circ} \mathrm{C}$ and $0.3 \pm 0.02 \% \mathrm{RH}$. The glass slides (i-iii) were kept on $20 \mathrm{~mm}$ high glass platforms in Azlon plastic boxes tightly covered with lid $(100 \times 100 \times 50 \mathrm{~mm})$ or (iv) in Duroplan borosilicate glass petri dishes $(100 \times 30 \mathrm{~mm}$ Duran Group GmbH, Mainz, Germany) at room temperature without particular treatment (i), at room temperature with an Aqua-millipore-water-layer covered bottom of boxes (ii), at room temperature with a Silica-gel covered bottom of boxes (iii), and in a heating oven (Memmert GmbH \& Co. KG, Schwabach, Deutschland) (iv). The temperature and relative humidity were recorded using data loggers EL-USB-2+ (Lascar Electronics Ltd, Salisbury, Wiltshire, UK).

Contact angle measurements. The contact angle measuring device OCA25 equipped with a high-speed CCD video system and SCA20 4.5.17 software (Data-Physics Instruments GmbH, Filderstadt, Germany) was 
used with Aqua millipore water, oil, and differently conditioned bud secretion on various substrates according to the free sessile drop method. Normal and silanized glass, as well as Teflon, were used as control surfaces. For each substrate and condition of secretion, the contact angle of 10 secretion droplets was measured $(\sim 2 \mu \mathrm{g}$, $0.03 \mathrm{~mm}^{3}$ ). The contact angle of 10 water and oil 2- $\mu \mathrm{L}$ droplets (ExxonMobil oil AM Core 100, Exxon Mobil Corp., Spring, TX, USA) was estimated on a horse-chestnut bud and a female American cockroach forewing. In total, 165 contact angle measurements were conducted.

Raman spectroscopy. Using a piece of a clean glass slide, about $3 \mathrm{mg}$ of secretion was sloughed-off from the living buds, placed on another clean glass slides, and directly analyzed. We applied Raman spectroscopy because it is a suitable analytical tool for a limited volume of natural (non-treated) adhesive plant secretion, facilitating focus on minimum $200 \times 250 \mathrm{~nm}$ to average $250 \times 500 \mathrm{~nm}$ spot size of samples.

The measurements were carried out at the Papiertechnische Stiftung (PTS, Heidenau, Germany) using a WITec alpha 300M+ confocal Raman microscope equipped with $532 \mathrm{~nm}$ laser excitation (WITec Wissenschaftliche Instrumente und Technologie GmbH, Ulm, Germany). This system is based on a Zeiss light microscope and was used with a $50 \times$ objective (Zeiss EC Epiplan NA 0.75; Carl Zeiss Microscopy GmbH, Jena, Germany) using $20 \mathrm{~mW}$ laser power and a $600 \mathrm{~g} \mathrm{~mm}^{-1}$ grating. Raman spectra were obtained from visibly non-contaminated bud secretion areas using $0.5-1 \mathrm{~s}$ exposure time and 100 accumulations. The Raman spectrum shown is an average of five different individual spots. Before averaging, the spectra were background-corrected and normalized.

ATR FTIR. Secretion samples were prepared as described above. Attenuated total reflection Fourier-transform infrared (ATR FTIR) spectra were recorded using a Nicolet iS 5 FT-IR-spectrometer (Thermo Scientific Inc., Waltham, MA, USA) coupled to a Golden Gate Single Reflection ATR system P/N 10563 with a diamond top plate at $45^{\circ}$ (Specac Ltd., Orpington, Kent, UK). ATR FTIR has been previously demonstrated to be a reliable method to analyze biological samples ${ }^{69,70}$. A spectral resolution of $1 \mathrm{~cm}^{-1}$ was chosen over the spectral range of $4000-600 \mathrm{~cm}^{-1}$. One hundred scans were accumulated for each spectrum. The spectrum shown is an average of three different individual measurements, which were ATR and baseline corrected using the OMNIC 9 Software (Thermo Scientific Inc., Waltham, MA, USA). Database search was performed using the software OMNIC Specta 2.1 (Thermo Scientific Inc.) using the Nicolet Standard Collection of Raman Spectra and Organics by Raman sample database.

Force measurements. A custom-built tribometer ${ }^{71}$ that enables flat samples to self-align ${ }^{72}$, and that can operate inside the Quanta 250 environmental SEM (FEI, Brno, Czech Republic) was used to measure pull-off forces. In this work, all force measurements were performed outside the SEM, and the latter, in combination with the xT microscope Control software (FEI, Brno, Czech Republic), was used only to visualize different types of contact separation with differently conditioned bud secretion on normal glass and cockroach forewing. When the tribometer was operated outside the SEM, a monochrome digital camera DMK 23UP1300 (Imaging Source, Charlotte, NC, USA) mounted on a high-magnification optical lens Zoom-12 (Navitar, Rochester, NY, USA) was used to capture videos of the glass-bud secretion interface.

Using plastic pipette tips (epT.I.P.S. Standard/Bulk 0.1-20 $\mu$ L, Eppendorf AG, Hamburg, Germany; inner and outer diameter of $436 \mu \mathrm{m}$ and $901.3 \mu \mathrm{m}$, respectively), single droplets of bud secretion (droplet volume $0.02 \pm 0.007 \mathrm{~mm}^{3}, \mathrm{n}=20$; droplet mass $1.6 \pm 0.77 \mu \mathrm{g}, \mathrm{n}=10$ ) were sloughed off from the bud surface or precollected secretion bulks on glass slides and then placed on a clean normal glass slide or on an evenly fixed female American cockroach forewing. After mounting the glass slide or the wing with the secretion droplet on the tribometer sample holder, the counter glass slide was moved perpendicular to the contact plane until a specific normal load was achieved. Next, the counter glass slide was withdrawn from the contact at a constant speed. The test stopped at a complete detachment of the glass slide when the force dropped to $0 \mathrm{mN}$ at about $100 \mu \mathrm{m}$ of displacement.

Six types of experiments were carried out: (i) a series of 100 pull-off force tests, with the same sample preloaded to $10 \mathrm{mN}$ for $5 \mathrm{~s}$, performed at a speed of $100 \mu \mathrm{m} \mathrm{s}^{-1}$, to test the reliability of secretion $(\mathrm{N}=3$ samples, $\mathrm{n}=100$ tests per sample); (ii) pull-off force tests performed as a function of the pull-off speed, comparing 10, $20,40,80,160$, and $320 \mu \mathrm{m} \mathrm{s}^{-1}(\mathrm{~N}=3, \mathrm{n}=5)$; (iii) pull-off force tests performed as a function of preload applied for $5 \mathrm{~s}$, comparing $2,5,10,20,40$, and $80 \mathrm{mN}$; (iv) pull-off force tests performed after a preload of $10 \mathrm{mN}$ for $5 \mathrm{~s}$ at a speed of $100 \mu \mathrm{m} \mathrm{s}^{-1}$ on three substrates (chitinous forewing of a female American cockroach, Teflon: polytetrafluorethylene, normal glass); (v) pull-off force tests performed after a preload of $10 \mathrm{mN}$ for $5 \mathrm{~s}$ at a speed of $100 \mu \mathrm{m} \mathrm{s}^{-1}$ with five differently conditioned secretion samples placed on a normal glass after keeping it for 7 days (v1) non-treated (in air at $22.3 \pm 1.00{ }^{\circ} \mathrm{C}$ and $32.3 \pm 4.42 \% \mathrm{RH}$ ), (v2) froozen (in air at $-15.5 \pm 2.02^{\circ} \mathrm{C}$ and $51.4 \pm 7.03 \% \mathrm{RH}$ ), (v3) heated (in air at $50^{\circ} \mathrm{C}$ and $0.3 \% \mathrm{RH}$ in the Thermo Scientific VACUtherm vacuum oven VT6025, Thermo Electron LED GmbH, Langenselbold, Germany), (v4) UV-irradiated at $365 \mathrm{~nm}$ (UVP UVGL-25, Analytik Jena US, Upland, CA, USA; in air at $22.3 \pm 1.00^{\circ} \mathrm{C}$ and $32.3 \pm 4.42 \% \mathrm{RH}$ ), and (v5) hydrated (submersed in Aqua millipore water at $22.3 \pm 1.00{ }^{\circ} \mathrm{C}$ and $\left.100 \pm 0 \% \mathrm{RH}\right)(\mathrm{N}=10, \mathrm{n}=3$ ); (vi) pull-off force tests performed inside the SEM with a simultaneous highly-magnified imaging of the secretion-substrate interface. The SEM was operated at a low vacuum $(300 \mathrm{~Pa})$, at $12.5 \mathrm{kV}, 92-96 \mu \mathrm{A}$, spot size 6 , and a working distance of 6-12 $\mathrm{mm}$. The gaseous secondary electron detector was used to visualize the non-coated samples at a rate of one image (scan) per second. Movies were created by combining the freeze frames. The secretion layer thickness under preload was measured using the obtained SEM micrographs.

After testing, the secretion samples on the glass and cockroach wing substrates were imaged with a stereomicroscope Leica 12.5 combined with the camera Leica DFC450 and the Leica Application Suite software 
4.7.1 (Leica Mikrosysteme Vertrieb GmbH, Wetzlar, Germany) to estimate the contact area using the SigmaScan Pro 5.0.0 software.

Before testing a new sample, the glass substrate was cleaned by successively rinsing it with acetone and Aqua Millipore water, and then drying it with compressed air.

Statistics. Using SigmaPlot 12.0 software (Systat Software, San Jose, CA, USA), normally and non-normally distributed data were compared with $t$ test and one-way ANOVA or Mann-Whitney rank-sum test and KruskalWallis one-way ANOVA on ranks, respectively. Relationships were evaluated with linear (LR) and nonlinear regressions (NR).

\section{Data availability}

All data needed to evaluate the conclusions in the paper are present in the article and/or the Supplementary Materials. Additional data related to this paper may be requested from the authors.

Received: 15 May 2020; Accepted: 22 September 2020

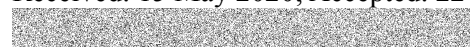

\section{References}

1. Oetken, I. Anatomie und Feinstruktur der Colleteren von Aesculus hippocastanum L. Dissertation, MathematischNaturwissenschaftliche Fakultät der Universität Bonn (1969).

2. Charriere-Ladreix, Y. L. Sécrétion lipophile des bourgeons d'Aesculus hippocastanum L.: modifications ultrastructurales des trichomes au cours du processus glandulaire. J. Microsc. Biol. Cell. 24, 75-90 (1975).

3. Hanstein, J. Ueber die Organe der Harz- und Schleim-Absonderung in den Laubknospen. Bot. Ztg. 26, 689-787 (1868).

4. Nachtigall, W. Biological Mechanisms of Attachment. The Comparative Morphology and Bioengineering of Organs for Linkage, Suction, and Adhesion (Springer, Berlin, 1974).

5. Dell, B. \& McComb, A. J. Plant resins-their formation, secretion and possible functions. Adv. Bot. Res. 6, 277-316 (1978).

6. Fahn, A. Secretory Tissues in Plants (Academic Press, London, 1979).

7. Thomas, V. Structural, functional and phylogenetic aspects of the colleter. Ann. Bot. 68, 287-305 (1991).

8. Vitarelli, N. C. \& Santos, M. Anatomia de estípulas e coléteres de Psychotria. Acta Bot. Bras. 23, 923-928 (2009).

9. Mercadante-Simões, M. O. \& Sousa Paiva, E. A. Leaf colleters in Tontelea micrantha (Celastraceae, Salacioideae): ecological, morphological and structural aspects. Comptes Rendus Biol. 336, 400-406 (2013).

10. Cotta Coutinho, Í. A., Teodoro Francino, D. M., Strozi, R. M. \& Meira, A. New records of colleters in Chamaecrista (Leguminosae, Caesalpinioideae s.l.): structural diversity, secretion, functional role, and taxonomic importance. Int. J. Plant Sci. 176, 72-85 (2015).

11. Slatyer, R. O. Efficiency of water utilization by arid zone vegetation. Ann. Arid Zone 3, 1-12 (1964).

12. Hellmuth, E. O. Eco-physiological studies on plants in arid and semi-arid regions in Western Australia: III. Comparative studies on photosynthesis, respiration and water relations of ten arid zone and two semi-arid zone plants under winter and late summer climatic conditions. J. Ecol. 59, 225-259 (1971).

13. Dell, B. Distribution and function of resins and glandular hairs in Western Australian plants. J. R. Soc. Western Australia 59, 119-122 (1977).

14. Tschirch, A. \& Walliczek, H. Untersuchungen über die Sekrete. 3. Studien über die Membranschleime der vegetativen Organe offizineller Pflanzen. Arch. Pharm. Pharm. Med. Chem. 231, 313-320 (1893).

15. Christodoulakis, N. S., Tsimbani, H. \& Fasseas, C. Leaf structural peculiarities in Sarcopoterium spinosum, a seasonally dimorphic subshrub. Ann. Bot. 65, 291-296 (1990).

16. Fahn, A. \& Cutler, D. F. Xerophytes Encyclopedia of Plant Anatomy, Band XIII Teil 3 (Schweizerbart'sche Verlagsbuchhandlung, Stuttgart, 1992).

17. Curtis, J. D. \& Lersten, N. R. Morphology, seasonal variation, and function of resin glands on buds and leaves of Populus deltoides (Salicaceae). Am. J. Bot. 61, 835-845 (1974).

18. Miguel, E. C., Gomes, V. M., de Olveira, M. A. \& Da Cunha, M. Colleters in Bathysa nicholsonii K. Schum. (Rubiaceae): ultrastructure, secretion protein composition, and antifungal activity. Plant Biol. 8, 715-722 (2006).

19. Sampaio Mayer, J. L., Carmello-Guerreiro, S. M. \& Mazzafera, P. A functional role for colleters of coffee flowers. AoB Plants 5, plt029 (2013).

20. Ribeiro, J. C., Pena Ferreira, M. J. \& Demarco, D. Colleters in Asclepiadoideae (Apocynaceae): protection of meristems against desiccation and new functions assigned. Int. J. Plant Sci. 178, 465-477 (2017).

21. Tresmondi, F., Nogueira, A., Guimarães, E. \& Rodrigues Machado, S. Morphology, secretion composition, and ecological aspects of stipular colleters in Rubiaceae species from tropical forest and savanna. Sci. Nat. 102, 73 (2015).

22. Fehér, D. Über die Abscheidung von Harzbalsam auf den jungen Trieben unserer einheimischen Populus-Arten. Beihefte Botanisches Centralblatt 39, 81-1003 (1922).

23. Egger, K., Wollenweber, E. \& Tissot, M. Freie Flavonol-Aglykone im Knospensekret von Aesculus Arten. Z. Pflanzenphysiol. 62, 464-466 (1970).

24. Wollenweber, E. Methylierte Flavonol-Aglyka bei Aesculus. Z. Pflanzenphysiol. 73, 277-280 (1974).

25. Charriere-Ladreix, Y. Caractères de l'accumulation flavonique dans les tissus des organes sécréteurs des bourgeons d'Aesculus hippocastanum L. Z. Pflanzenphysiol. 73, 95-102 (1974).

26. Charriere-Ladreix, Y. Sur la presence de deux isoenzymes de la phenylalanine-ammoniac-lyase chez Aesculus hippocastanum. Phytochemistry 14, 1727-1731 (1975).

27. Langenheim, J. H. Plant Resins: Chemistry, Evolution, Ecology, and Ethnobotany (Timber Press, Portland, 2003).

28. Drescher, N., Klein, A.-M., Schmitt, T. \& Leonhardt, S. D. A clue on bee glue: new insight into the sources and factors driving resin intake in honeybees (Apis mellifera). PLoS ONE 14, e0210594 (2019).

29. Kumar, S. \& Pandey, A. K. Chemistry and biological activities of flavonoids: a review. Sci. World J. 2013, 162750 (2013).

30. Socrates, G. Infrared and Raman Characteristic Group Frequencies. Tables and Charts 3rd edn. (Wiley, Chichester, 2001).

31. Hummel, D. O. \& Scholl, F. Atlas of Polymer and Plastics Analysis 2nd edn. (Verlag Chemie International, Munich, 1978).

32. RoyChoudhury, S. et al. Uricase based enzymatic biosensor for non-invasive detection of uric acid by entrapment in PVA-SbQ polymer matrix. Electroanalysis 30, 2374-2385 (2018).

33. Czamara, K. et al. Raman spectroscopy of lipids: a review. J. Raman Spectrosc. 46, 4-20 (2014).

34. Jamieson, L. E., Li, A., Faulds, K. \& Graham, D. Ratiometric analysis using Raman spectroscopy as a powerful predictor of structural properties of fatty acids. R. Soc. Open Sci. 5, 181483 (2018).

35. Weng, Y.-M., Weng, R.-H., Tzeng, C.-Y. \& Chen, W. Structural analysis of triacylglycerols and edible oils by near-infrared Fourier Transform Raman Spectroscopy. Appl. Spectrosc. 57, 413-418 (2003). 
36. Eby, L. T. \& Brown, H. P. Thermosetting adhesives. In Treatise on Adhesion and Adhesives, Volume 2: Materials (ed. Patrick, R. L.) 77-169 (Marcel Dekker, New York, 1969).

37. Döring, A. Rasterkraftmikroskopische Untersuchungen an Haftklebstoffen. Dissertation, Fakultät für Naturwissenschaften der Universität Ulm, Ulm (2001).

38. Huang, S. Biodegradation. In Comprehensive Polymer Science and Supplements Vol. 6 (eds Allen, G. \& Bevington, J. C.) 97-606 (Elsevier, Amsterdam, 1989).

39. Anonymus. Polyamide hotmelt adhesives: an unquestionable innovation content. Macplas International At Fakuma, October 2017, 76-77 (2017).

40. Witten, T. \& Pincus, P. Structured Fluids. Polymers, Colloids, Surfactants (Oxford Universtity Press, New York, 2004).

41. Aarathi, V., Harshita, E., Nalinashan, A., Ashok, S. \& Prasad, S. R. Synthesis and characterisation of rubber seed oil trans-esterified biodiesel using cement clinker catalysts. Int. J. Sustain. Energ. 38, 333-347 (2019).

42. Meier, M. Pflanzenöle für die chemische Industrie. Nachr. Chem. 56, 738-742 (2008).

43. Weiler, E. W. \& Nultsch, W. Allgemeine und molekulare Botanik (Georg Thieme Verlag, Stuttgart, 2008).

44. Wollenweber, E. \& Egger, K. Methyläther des Myrcetins, Quercetins und Kämpferols im Knospenöl von Aesculus hippocastanum. Tetrahedron Lett. 19, 1601-1604 (1970).

45. Wollenweber, E. \& Jay, M. Flavones and flavonols. In The Flavonoids (ed. Harborne, J. B.) 233-328 (Chapman and Hall, London, 1988).

46. Dahlquist, C. A. Pressure-sensitive adhesives. In Treatise on Adhesion and Adhesives, Volume 2: Materials (ed. Patrick, R. L.) 219-260 (Marcel Dekker, New York, 1969).

47. Creton, C. Pressure-sensitive adhesives: an introductory course. MRS Bull. 28, 434-439 (2003).

48. Feldstein, M. M. Molecular nature of pressure-sensitive adhesion. In Fundamentals of Pressure Sensitivity Vol. 10 (eds Benedek, I. \& Feldstein, M. M.) 1-43 (CRC Press, Boca Raton, 2009).

49. Lakrout, H., Sergot, P. \& Creton, C. Direct observation of cavitation and fibrillation in a probe tack experiment on model acrylic pressure-sensitive-adhesives. J. Adhes. 69, 307-359 (1999).

50. Soboleva, O. A., Semakov, A. V., Antonov, S. V. \& Kulichikhin, V. G. Surface phenomena on a solid-liquid interface and rheology of pressure sensitivity. In Fundamentals of Pressure Sensitivity Vol. 1 (eds Benedek, I. \& Feldstein, M. M.) 1-23 (CRC Press, Boca Raton, 2009).

51. Chalykh, A. E. \& Shcherbina, A. A. Transition zones in adhesive joints. In Fundamentals of Pressure Sensitivity (eds Benedek, I. \& Feldstein, M. M.) 1-21 (CRC Press, Boca Raton, 2009).

52. Derail, C. \& Marin, G. Role of viscoelastic behavior of pressure-sensitive adhesives in the course of bonding and debonding processes. In Fundamentals of Pressure Sensitivity Vol. 4 (eds Benedek, I. \& Feldstein, M. M.) 1-26 (CRC Press, Boca Raton, 2009).

53. Gay, C. \& Leibler, L. Theory of tackiness. Phys. Rev. Lett. 82, 936-939 (1999).

54. Creton, C. \& Lakrout, H. Micromechanics of flat-probe adhesion tests of soft viscoelastic polymer films. J. Polym. Sci. B Polym. Phys. 38, 965-979 (2000).

55. Deplace, F. et al. Fine tuning the adhesive properties of a soft nanostructured adhesive with rheological measurements. J. Adhes. 85, 18-54 (2009).

56. Baljon, A. R. C. \& Robbins, M. O. Energy dissipation during rupture of adhesive bonds. Science 271, 482-484 (1996).

57. Bodamer, G. W. \& Kunin, R. Behavior of ion exchange resins in solvents other than water. Ind. Eng. Chem. 45, 2577-2580 (1953).

58. Miller, W. S., Castagna, C. J. \& Pieper, A. W. Understanding ion-exchange resins for water treatment systems. GE Water Process Technolol. TP1050EN, 1-13 (2009).

59. Voigt, D., Konrad, W. \& Gorb, S. Adhesive secretion in the flypaper plant Roridula gorgonias: glueing underwater. J. R. Soc. Interface Focus 5, 20140053 (2015).

60. Lakrout, H., Creton, C., Ahn, D. \& Shull, K. R. Micromechanisms of adhesion of pressure sensitive adhesives. In Proceedings of the European Conference on Macromolecular Physics-Surfaces and Interfaces in Polymers and Composites. Lausanne, Switzerland, 1st-6th June 1997, 253-254 (1997).

61. Eisner, T. \& Aneshansley, D. J. Adhesive strength of the insect-trapping glue of a plant (Befaria racemosa). Ann. Entomol. Soc. Am. 76, 295-298 (1983).

62. Frenzke, L. et al. Plant pressure sensitive adhesives: similar chemical properties in distantly related plant lineages. Planta 244, 145-154 (2016).

63. Soltis, D. et al. Phylogeny and Evolution of the Angiosperms: Revised and Updated Edition (University of Chicago Press, Chicago, 2018).

64. Habenicht, G. Kleben: Grundlagen, Technologien, Anwendung Vol. 6 (Springer, Berlin, 2009).

65. Luo, Z., Wan, X., Liu, C. \& Fan, L. Mechanistic insights of the controlled release properties of amide adhesive and hydroxyl adhesive. Eur. J. Pharm. Sci. 119, 13-21 (2018).

66. Yamano, N., Kawasaki, N., Oshima, M. \& Nakayama, A. Polyamide 4 with long-chain fatty acid groups-suppressing the biodegradability of biodegradable polymers. Polym. Degrad. Stab. 108, 116e122 (2014).

67. Beament, J. W. L. Wax secretion in the cockroach. J. Exp. Biol. 32, 514-538 (1955).

68. Bräuer, P., Neinhuis, C. \& Voigt, D. Attachment of honeybees and greenbottle flies to petal surfaces. Arthropod Plant Interact. 11, 171-192 (2017).

69. Pytlik, N., Butscher, D., Machill, S. \& Brunner, E. Diatoms-a "green" way to biosynthesize gold-silica nanocomposites?. Z. Phys. Chem. 232, 1353-1368 (2018).

70. Baker, M. J. et al. Using Fourier transform IR spectroscopy to analyze biological materials. Nat. Protoc. 9, 1771-1791 (2014).

71. Murarash, B. \& Varenberg, M. Tribometer for in situ scanning electron microscopy of microstructured contacts. Tribol. Lett. 41, 319-323 (2011).

72. Varenberg, M., Peressadko, A., Gorb, S., Arzt, E. \& Mrotzek, S. Advanced testing of adhesion and friction with a microtribometer. Rev. Sci. Instrum. 77, 066105 (2006).

\section{Acknowledgements}

This study was funded by the COST Action ENBA (CA15216) ECOST-STSM-Request-CA15216-45318 to DV. We thank Enrico Pigorsch (Papiertechnische Stiftung PTS, Heidenau, Germany), who facilitated access to the Raman device. Tobias Pietsch and Silvia Paasch (Bioanalytical Chemistry, Technische Universität Dresden, Germany) kindly assisted with NMR measurements and evaluation, respectively. Jessica Bowman (School of Chemistry and Biochemistry, College of Sciences GeorgiaTech, Atlanta, GA, US) provided the UV lamp. Bernd Schulz (Institute for Botany, Faculty of Biology, Technische Universität Dresden, Germany) stimulated discussion on tree bud morphology. Ingelore and Michael Voigt (Zwickau/Sa., Germany) contributed to sampling and brainstorming. 


\title{
Author contributions
}

D.V. devised the project and prepared the material. D.V., J.K., A.J. ran the analyses. Interpretation was made by D.V., J.K., A.J., and M.V. The paper was written by D.V., J.K., A.J., and M.V. All authors have given approval to the final version of the manuscript.

\section{Funding}

Open Access funding enabled and organized by Projekt DEAL.

\section{Competing interests}

The authors declare no competing interests.

\section{Additional information}

Supplementary information is available for this paper at https://doi.org/10.1038/s41598-020-74029-5.

Correspondence and requests for materials should be addressed to D.V.

Reprints and permissions information is available at www.nature.com/reprints.

Publisher's note Springer Nature remains neutral with regard to jurisdictional claims in published maps and institutional affiliations.

\begin{abstract}
(c) (i) Open Access This article is licensed under a Creative Commons Attribution 4.0 International License, which permits use, sharing, adaptation, distribution and reproduction in any medium or format, as long as you give appropriate credit to the original author(s) and the source, provide a link to the Creative Commons licence, and indicate if changes were made. The images or other third party material in this article are included in the article's Creative Commons licence, unless indicated otherwise in a credit line to the material. If material is not included in the article's Creative Commons licence and your intended use is not permitted by statutory regulation or exceeds the permitted use, you will need to obtain permission directly from the copyright holder. To view a copy of this licence, visit http://creativecommons.org/licenses/by/4.0/.
\end{abstract}

(C) The Author(s) 2020 